Cite as: Kurtz, G., \& Peled, Y. (2016). Digital learning literacies - A validation study. Issues in Informing Science and Information Technology, 13, 145-158. Retrieved from http://www.informingscience.org/Publications/3479

\title{
Digital Learning Literacies - A Validation Study
}

\section{Gila Kurtz \\ The College for Academic Studies, Or-Yehuda, Israel}

Gilak@mla.ac.il

\author{
Yehuda Peled \\ Western Galilee \\ College, Acre, Israel
}

yehudap@wgalil.ac.il

\begin{abstract}
This paper presents a validation research of seven Digital Learning Domains (DLDs) and sixtyfive performance statements (PSs) as perceived by students with experience in learning via ICT. The preliminary findings suggest a statistical firmness of the inventory. The seven DLDs identified are Social Responsibility, Team-based Learning, Information Research and Retrieval, Information Management, Information Validation, Processing and Presentation of Information, and Digital Integrity. The 65 PSs will enable a teacher to identify the level of competency the learner has in each DLD, thus identifying students' strengths and weaknesses that must be addressed in order to facilitate learning in the current era.

As can be concluded from the findings, most of the participants evaluate themselves as digitally literate with regard to the basic information research and retrieval skills, validation and information management. But when it comes to PSs that require complex decision making or higher order thinking strategies, it seems that a large number of participants lack these skills. Also, social responsibility and digital integrity domains are perceived as known by the participants but not very well taken in terms of pro-active action to enforce appropriate digital behavior, or avoiding illegally obtained music or movies.
\end{abstract}

Key words: Digital Learning Literacies, $21^{\text {st }}$ Century Skills, Learning Skills

\section{Introduction}

A notable feature of our society is the rapid rate of technological and social changes, especially the emergence of web 2.0 technologies and the way its implication on social behavior reflects on changes in the digital literacy terminology. Various researchers have offered definitions of digital literacy (DL) (e.g., see Bawden, 2001; Gilster, 1997; Lankshear \& Knobel, 2008; Mioduser, Nachmias ,\& Forkosh-Baruch, 2008). Although there are numerous suggestions as to what the needed DLs are (e.g., see Dede, 2010; Dudeney, Hockly \& Pegrum, 2013; Eshet-Alkalai \& Amichai-Hamburger, 2004), there are few empirical tools to measure what DLs a learner has or

Material published as part of this publication, either on-line or in print, is copyrighted by the Informing Science Institute. Permission to make digital or paper copy of part or all of these works for personal or classroom use is granted without fee provided that the copies are not made or distributed for profit or commercial advantage AND that copies 1) bear this notice in full and 2) give the full citation on the first page. It is permissible to abstract these works so long as credit is given. To copy in all other cases or to republish or to post on a server or to redistribute to lists requires specific permission and payment of a fee. Contact Publisher@,InformingScience.org to request redistribution permission. needs (e.g., see Jung \& Latchem, 2011). The current research aims to fill the gap between the theory and the practice of DLs. The research is based on previous work by Beaudoin, Kurtz, Jung, Suzuki, and Grabowski (2013) who tested and validated a set of performance statements (PS) identifying twenty DLs needed by the learner in the second decade of the $21^{\text {st }}$ century. These PSs will enable a teacher to identify the level of 
competency the learner has in each DL, thus identifying students' strengths and weaknesses that must be addressed in order to facilitate learning in the current era.

This paper presents the results of an empirical study that enabled the research team to finalize the validation of PSs for an inventory of digital literacy skills required for learning. The purpose of the validation process is to gather empirical evidence regarding the criticality of seven Digital Learning Domains (DLD) and sixty-five performance statements as perceived by students with experience in learning via ICT. The seven DLDs identified are Social Responsibility, Team-based Learning, Information Research and Retrieval, Information Management, Information Validation, Processing and Presentation of Information, and Digital Integrity.

\section{Conceptual Framework}

The beginning of 'digital literacy' as a professional domain can be traced back to the end of the 1960s when it was perceived by scholars that the common definitions of 'literacy' missed out an important component from the increasingly visual nature of the media produced by society. In 1969 John Debes offered a tentative definition for a concept he called 'visual literacy': "Visual Literacy refers to a group of vision-competencies a human being can develop by seeing and at the same time having and integrating other sensory experiences. The development of these competencies is fundamental to human learning. When developed, they enable a visually literate person to discriminate and interpret the visible actions, objects, symbols - natural or manmade - that an individual encounters in his environment. Through the creative use of these competencies, he is able to communicate with others. Through the appreciative use of these competencies, she is able to comprehend and enjoy the masterworks of visual communication" (Debes, quoted in Avgerinou \& Ericson, 1997). Parallel to visual literacy from the 1970s onwards came the development of the term 'technological literacy', which was defined as combining "the ability to use ... the key systems of the time,' whilst 'insuring that all technological activities are efficient and appropriate,' and 'synthesiz[ing] ... information into new insights" (quoted in Martin, 2008, p. 158).

Growing out of the perceived need for a 'technological literacy' came, with the dawn of the personal computer, calls for definitions of a 'computer literacy' which can be found in the early 80s (e.g., Longstreet \& Sorant, 1985; Luehrmann, 1981; Watt, 1982). The National Science Foundation (NSF) held a 1980 conference that gathered computer scientists and classroom teachers to make the first attempts at defining computer literacy as well as indicating that it was a multifaceted idea (Anderson, 1982). The Texas Higher Education Coordinator Board mandated a statewide common core curriculum. The board defined computer literacy as the "ability to use computerbased technology in communicating, solving problems, and acquiring information" (Core Curriculum Evaluation Report, 2004, p. 1). Watt (1982) defines computer literacy as a "cultural phenomenon which includes the full range of skills, knowledge, understandings, values and relationships necessary to function effectively and comfortably as a citizen of a computer-based society" (p. 57).

The term 'information literacy' was coined in the 1970s but has undergone a number of transformations to keep it current and relevant. Unlike 'technological literacy,' 'computer literacy,' and 'Information Communication Technology (ICT) literacy,' it is not bound by technology and likely to become outdated, nor is it a correction to an existing 'literacy' (as with 'visual literacy'). Because it is not dependent upon any one technology or set of technologies, 'information literacy' has been eagerly taken onboard by librarians (Martin, 2008) and governments (Fieldhouse \& Nicholas, 2008) alike.

At the turn of the century, the term 'digital literacy' was introduced by Paul Gilster in his book Digital Literacy (Gilster, 1997). Gilster did not provide lists of skills, competences, or attitudes defining what it is to be digitally literate. Rather, he explained it, quite generally, as an ability to 
understand and to use information from a variety of digital sources and regarded it simply as literacy in the digital age. Gilster was not the first to use the phrase 'digital literacy.' It had been applied throughout the 1990s by a number of authors who used it to mean essentially an ability to read and comprehend information items in the hypertext or multimedia formats which were then becoming available (Bawden, 2001). Gilster's idea of digital literacy did not appear out of the blue. There was already a substantial amount of literature and practical experience around the ideas of information literacy and computer literacy - both of these terms (together with equivalents such as 'IT literacy') originated largely to describe sets of specific skills and competences needed for finding and handling information in computerized form. 'Computer literacy' was the term mainly in vogue through the 1980s, with 'information literacy' gaining popularity in the 1990s (Bawden, 2008). Lankshear and Knobel (2008) introduced the concept of digital literacies (in plural), as they believe it is important to emphasize the plurality of digital literacy because of (1) the sheer diversity of specific accounts of 'digital literacy' that exists and consequent implications of that for digital literacy policies; (2) the strength and usefulness of a socio-cultural perspective on literacy as practice, according to which literacy is best understood as literacies and by extension, then, digital literacy can usefully be understood as digital literacies - in the plural; (3) the benefits that may accrue from adopting an expansive view of digital literacies and their significance for educational learning.

Littlejohn, Beetham and McGill (2012) propose that digital literacy extends beyond technical competence, such as the ability to form letters in writing or use a keyboard. Digitally based knowledge practices are meaningful and generative of meaning - they depend on the learner's previous experiences, on dispositions such as confidence, self-efficacy, and motivation, and on qualities of the environment where that practice takes place, including, of course, the available digital technologies. Digital literacies are both constitutive of and expressive of personal identity. They are valuable only insofar as they are capable of evolution in light of changing technical, social, economic, cultural, and educational contexts.

Eshet-Alkalai and Amichai-Hamburger (2004) attempt a rigorous yet practical overview of digital literacy by using a 'skills' framework. Digital literacy thus includes:

1. Photo-visual skills ("“reading” instructions from graphical displays')

2. Reproduction skills ("utilizing digital reproduction to create new, meaningful materials from preexisting ones')

3. Branching skills ('constructing knowledge from non-linear, hyper textual navigation')

4. Information skills ('evaluating the quality and validity of information')

5. Socio-emotional skills ("understanding the "rules" that prevail in cyberspace and applying this understanding in online cyberspace communication') (p.421).

Their inventory marks the move to what is called ' 21 st Century Skills.' These are different skills than 20th century skills primarily due to the emergence of very sophisticated information and communications technologies (Dede, 2009). Numerous conceptual frameworks for ' 21 st Century Skills' were formulated between 2003 and 2007. Some of them have also formulated lists of 'digital literacies' as core capabilities for the 21 st century. Dede (2009) brings in his work 'Comparing Frameworks for 21 st Century Skills' a range of different conceptual frameworks for '21st Century Skills' and a review of the conceptual frameworks for digital literacies.

There are a number of ways of conceptualizing digital literacies. Dudeney et al. (2013) suggest a set of four overlapping skill sets corresponding to four main areas-language, information, connections, and (re-)design. The language-based literacies include not only traditional print literacy but also the skills to decode online text genres, such as blogs, wikis, or forum discussions. Pegrum (2011) also includes 'texting literacy' - the ability to read and create the abbreviated forms used in text messaging or in taking part in real-time online text chat conversations. Another 
facet is 'hypertext literacy' - the ability to navigate and read online texts which contain hyperlinks. Others are 'visual and multimedia literacy,' 'gaming literacy' (a macro literacy involving 'linguistic, multimedia, spatial and kinesthetic skills') and 'mobile literacy' - the skills needed to effectively use mobile or handheld devices (Dudeney et al., 2013). Finally, are 'technological literacy' and 'code literacy,' which include a basic understanding of coding so as not to be tied exclusively to the use of commercial templates in online tools and to have the ability to route around restrictions were deemed appropriate (Hockly, 2012). The Information-based literacies include 'search literacy' (the ability to search effectively for information online), 'tagging literacy' (labeling or tagging online materials so they are findable), 'information literacy' (being able to critically evaluate sources and information), 'filtering literacy' (knowing how to manage information overload), and 'attention literacy' (knowing when to switch off as well as on) (Dudeney et al., 2013). The Connection-based literacies include knowing how to manage your digital identity or online persona ('personal literacy') and 'network literacy,' which helps one filter information received from one's online networks while becoming a node in these networks by passing on relevant information or news (Pegrum, 2010). 'Participatory literacy' involves being able to create and produce digital content; this in turn includes 'cultural and intercultural literacy' when working with international virtual teams (Hockly, 2012).

Belshaw (2012) outlines eight key elements that characterize digital literacies:

1. Cultural: This is the need to understand different online contexts and how to interact appropriately in them.

2. Cognitive: This is about ways of conceptualizing 'digitality' rather than the practice of using tools.

3. Constructive: This includes the ability to create remixes.

4. Communicative: This is about understanding how communications media work.

5. Confident: We need to be confident users of technology and have enough technical expertise to be able to use technology for our own ends, rather than be manipulated by it.

6. Creative: This is the ability to find new ways to do new things with new tools.

7. Critical: This is the need to learn to 'curate' and critically understand the resources that we find and not just superficially skim over information.

8. Civic: This is about knowing how to use technology to increase civic engagement and social action.

The conceptual framework presented above lays the basis of the current research - to validate a set of digital learning literacies needed for $21^{\text {st }}$ century learners.

\section{Research Method}

\section{Instrument Development}

Based on the theoretical conceptual framework presented above as well as additional resources (e.g., Lau \& Yuen, 2014; Nelson, Courier, \& Joseph, 2011), developing a list of DLDs and PSs was compiled and distributed to six expert researchers in the educational technology field and seven graduate students of ICT learning at the College of Academic Studies in Israel for prevalidation review and comments. The experts and the students were asked to provide a critical review of the DLDs and PSs by responding to open-ended questions related to fitness, appropriateness, missing items, revision, rephrasing, and clarity. Their comments were analyzed by the research team to determine what, if any, revisions to the DLDs should be included in the survey 
that was to be used in the current validation research. Based on respondent input, a final set of seven DLD and sixty-five Likert-type scale items from 1 to 5 was listed in the current survey. In order to assess the internal consistency of the survey, Cronbach's alpha reliability tests were run on each domain. A high alpha value ( 0.7 and above) is often used as evidence that the items measure an underlying (or latent) construct. Also, alpha coefficients may be used to describe the reliability of the instrument (Nunnally, 1978). As shown in Figures 1 to 7, each of the 7 DLDs got a high alpha value.

\section{Participants and Data Collection}

The sampling frame for this research was all 1,889 students at the Western Galilee College in Israel. They were invited by e-mail to respond to an online questionnaire. Collection of the questionnaire data was carried out during May and June 2015. Two hundred and fifty-three students filled out the questionnaire (13.4\% response rate). The majority of respondents $(76.9 \%)$ were female while $23.1 \%$ were male. This ratio might be biased for the general population but it is in accordance with the gender distribution at the college. Half of the respondents are between 25 and 40 years old $(\mathrm{Mean}=27.8, \mathrm{SD}=9.5)$. Almost all the respondents $(98.4 \%)$ were undergraduate students at the Department of Education.

\section{Findings}

\section{Social Responsibility}

As shown in Figure 1, most of the participants are very much aware and can protect themselves in threatening situations. Most of them are very much aware of the dangers to themselves and others, from cyberbullying to identity theft issues to the theft of their data. They understand very well the social consequences of their online activities as well as their ethical consequences and adhere to the rules of discourse and proper behavior in social networks. Also, they think they know very well how to protect themselves from online predators or identify and avoid online situations involving fraud, identity theft and impersonation. Most of the participants will not take any action that might hurt others - they make sure to a large extent not to hurt others and will not use technology if there is a chance that someone will be hurt from it, or for illegal purposes, or for purposes that are intimidating, threatening or harassing to others. Also, almost $80 \%$ are very careful not to reveal online personal information about others or about organizations without the consent of the person or organization concerned. Yet, a relatively high percentage will not take any action when they come across an inappropriate dialogue online. They neither report inappropriate dialogue online nor make any comment on it.

It can be concluded that despite having the awareness about what is appropriate behavior over the net, a significant percentage of respondents do not take any pro-active measures to enforce them. 


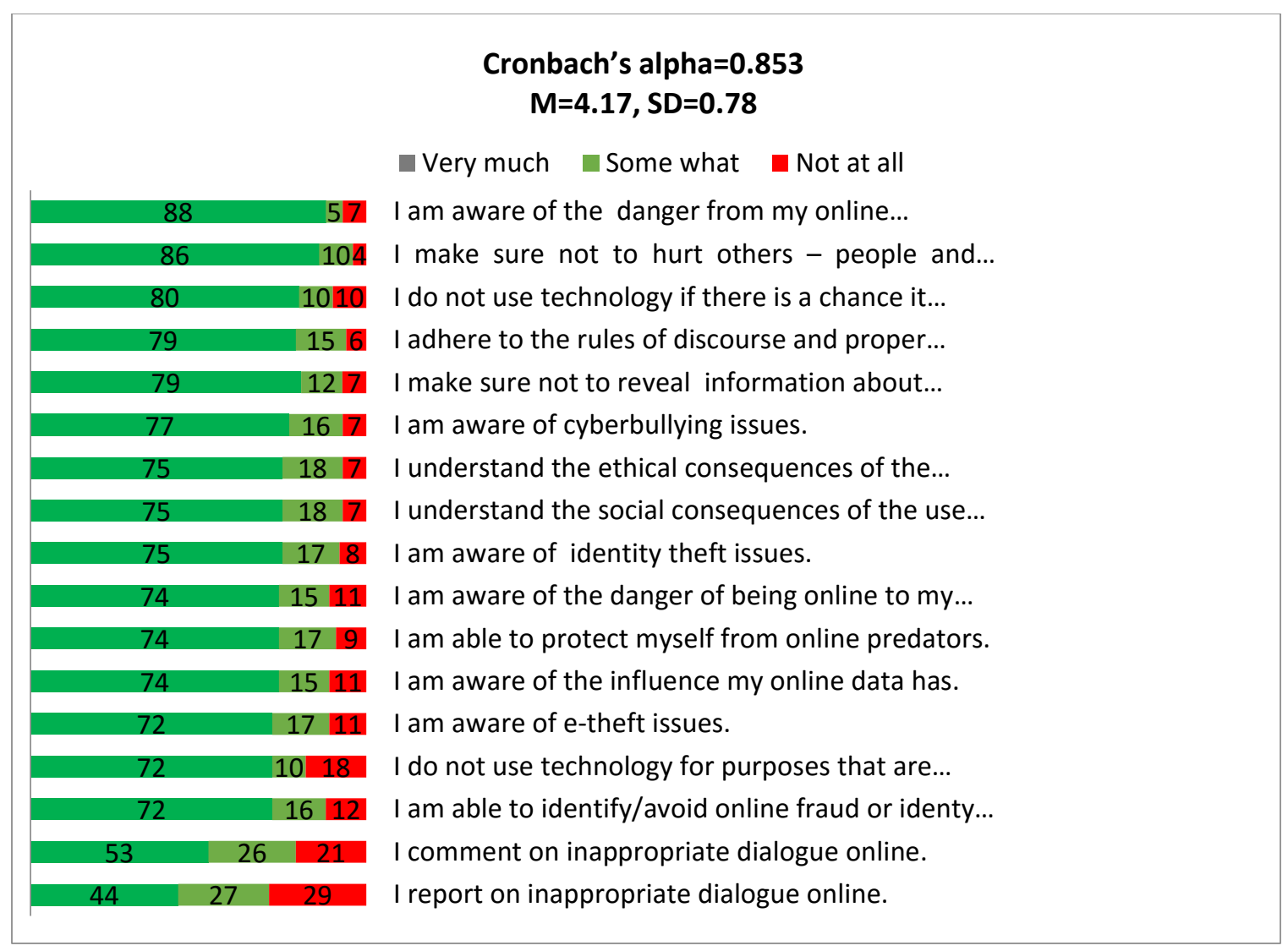

Figure 1: Social Responsibility 


\section{Team-Based Learning}

As demonstrated in Figure 2, most respondents believe they know very well how to manage their learning with peers. $84 \%$ feel that their contribution to the team while performing a joint task is meaningful to a large extent. The same percentage estimates that their peers are aware of the respondent's ability and contribution to the team work. A vast majority say that during the preparation of a joint task they know to a large extent what is expected of them, share their thoughts and insights with their peers, know that they have influence on the work process, know how to fit in among team members and have no reservations regarding joint tasks. On the other hand, $46 \%$ claim that they much prefer to work independently and 30\% say they do not like to work with peers on a joint task.

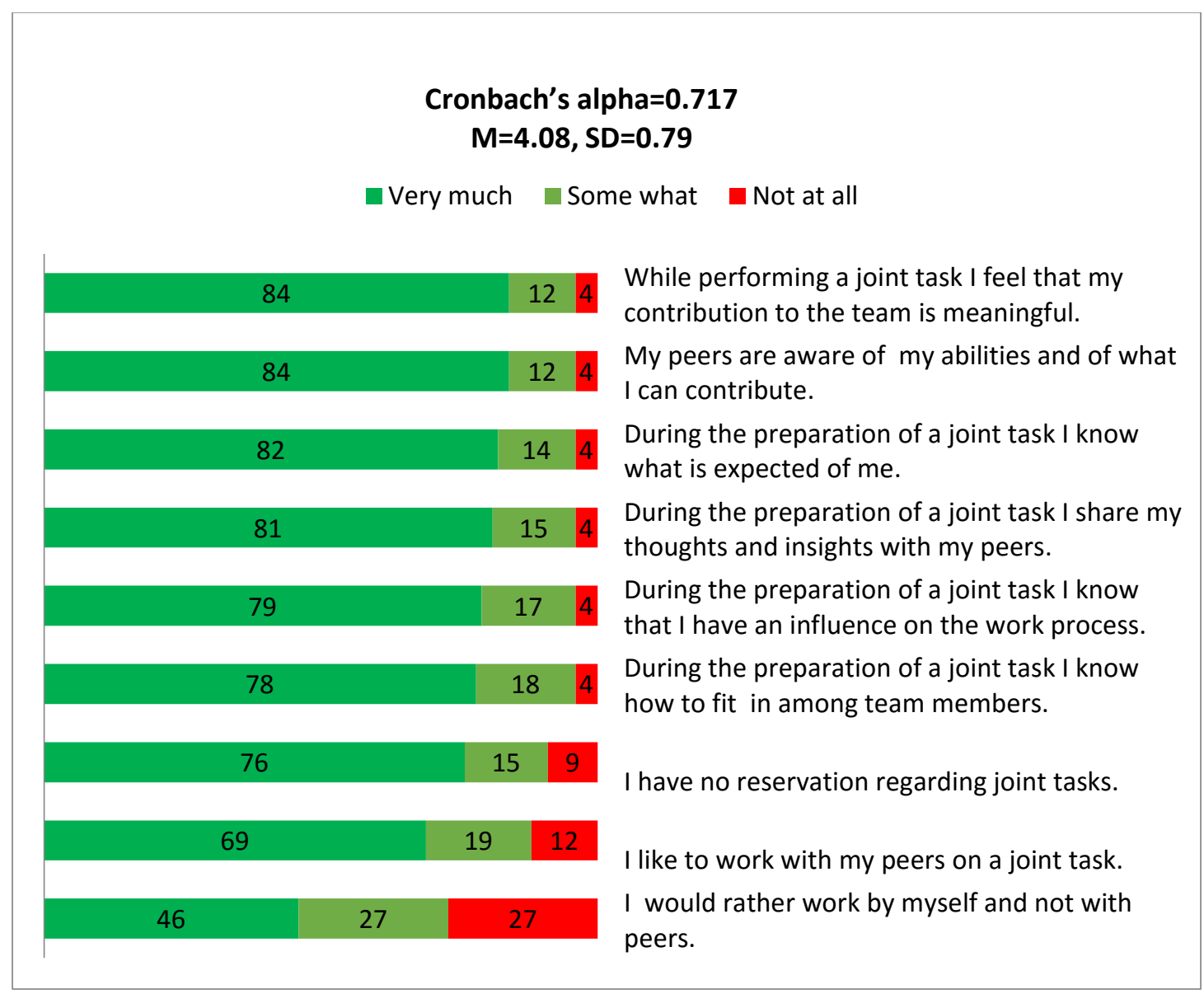

Figure 2: Team-Based Learning 


\section{Information Research and Retrieval}

Figure 3 shows that the vast majority of respondents feel very confident in their ability to collect and retrieve digital information-80\% say that they are able to collect information from the web. More than $70 \%$ say that, to a large extent, when they need to look for information they know how to search effectively, they can define the objective of the search, they can articulate what information is needed for their research, they are able to re-locate a specific web page, distinguish between precise and comprehensive research, and identify the information needed for their research. Another set of performance statements examined data identification and retrieval — one third said that, to a large extent, they lack the ability to identify file types by their extensions, re-locate specific information and retrieve information from various digital environments. Also, when asked to evaluate their research abilities by defining research terms and collecting information from online data bases, almost $50 \%$ feel they partially or totally lack this research ability.

These findings indicate that most participants have basic information research and retrieval skills. When it comes to PSs that require complex decision making, it seems that a large number of participants lack this skill.

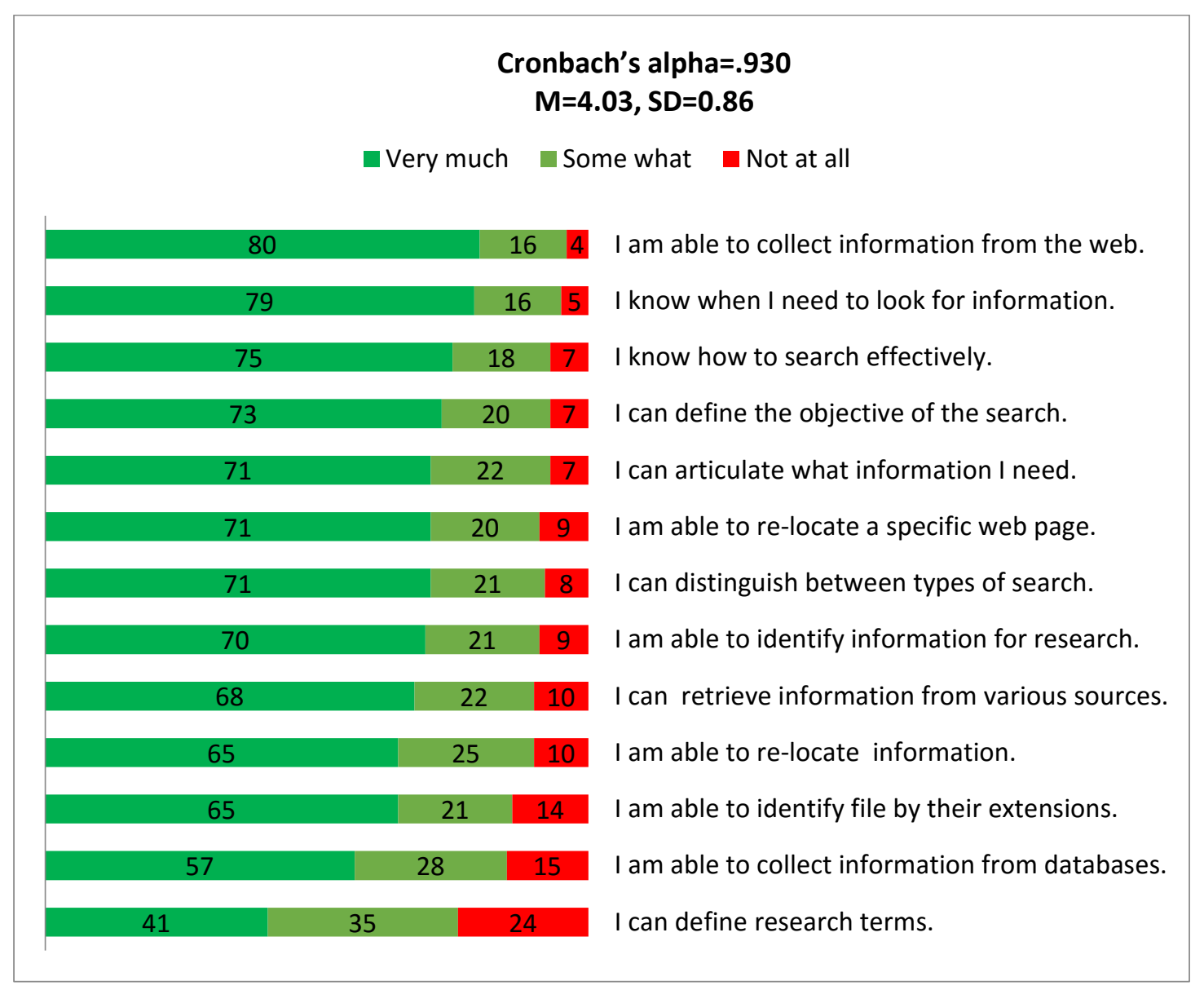

Figure 3: Information Research and Retrieval 


\section{Information Management}

As shown in Figure 4, most of the respondents believe they manage their files, data, and folders carefully-78\% say they give a specific name to each file they store, $74 \%$ tag their information. A bit less than that, but still more than $60 \%$ of the respondents, store their files in designated folders and are quite able to locate previously stored information.

These findings indicate that most of the participants evaluate themselves as digitally literate with regard to the information management domain.

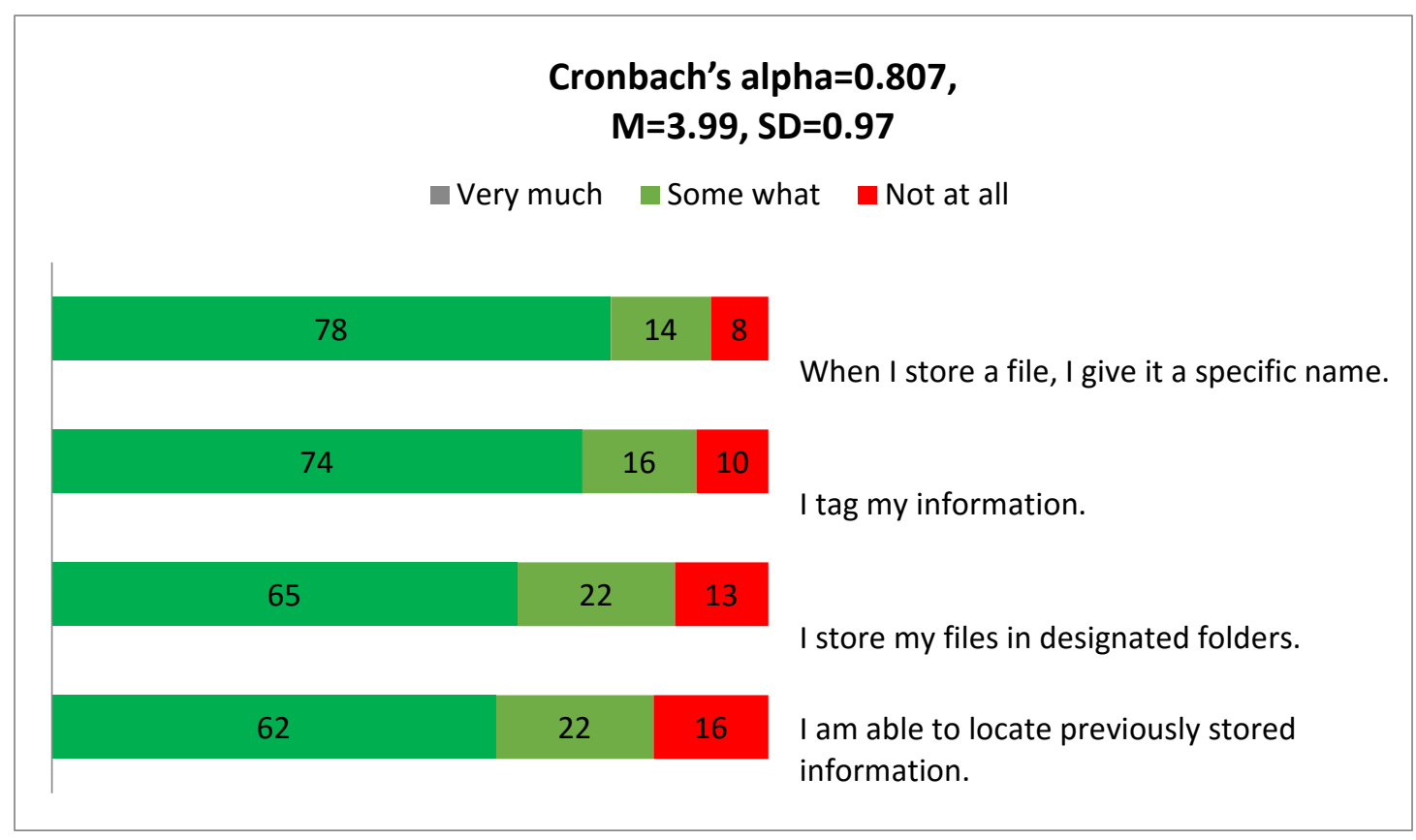

Figure 4: Information Management 


\section{Information Validation}

As described in Figure 5, the majority of respondents view themselves as being able to validate online information very well. $77 \%$ say they are able to judge the degree to which information is practical or satisfies the needs of their learning task. $70 \%$ continue to search content beyond the first six 'hits'. More than $60 \%$ say they are able to assess the accuracy of information, are aware of the difference in credibility of information from various sources, and are able to determine what information is required for a specific task. On the other hand, $20 \%$ admitted that they are not able at all to determine what information is required for a specific task. This last finding is disturbing since it means that some students perform the learning task without knowing how to choose which information to allocate for a specified task.

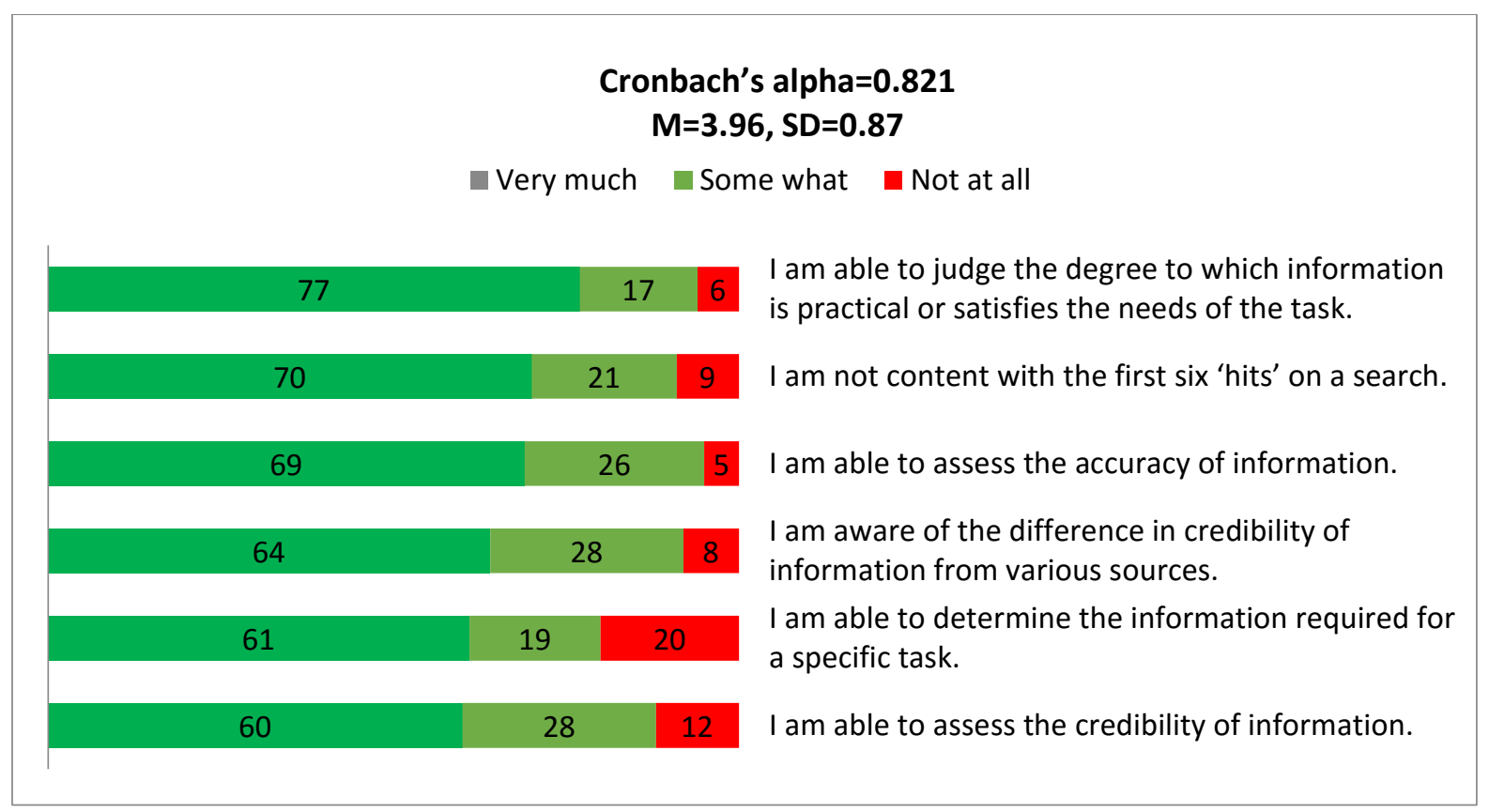

Figure 5: Information Validation 


\section{Processing and Presentation of Information}

Figure 6 reveals that although the majority of the participants say they are very much aware of the differences in written, graphic or video representations, over 30\% admit that they lack working skills related to higher order thinking strategies, especially in representing knowledge in a variety of digital formats and interpreting information from multiple sources.

These findings imply that a considerable share of the participants lack the learning skills essential for a meaningful learning process, which might lead to shallow learning outcomes.

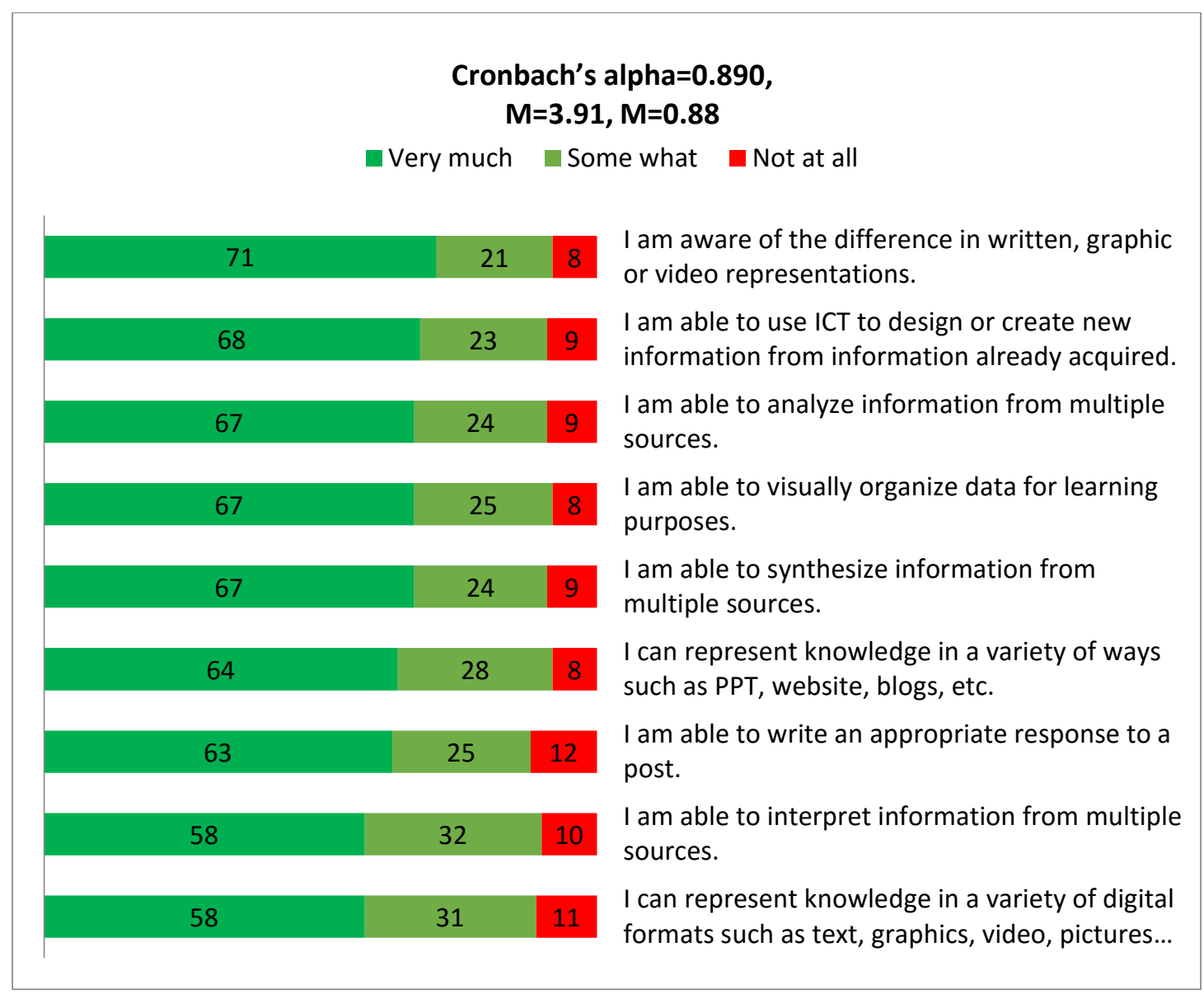

Figure 6: Processing and Presentation of Information 


\section{Digital Integrity}

Based on the findings shown in Figure 7, the majority of the respondents say they are very much aware of the various dimensions of digital integrity. Most of the participants are aware of copyright issues; they will not acquire digital data via illegal means or use technology for illegal purposes and they say they are aware of prohibition of illegal file download. On the other hand, almost half of the respondents say they do not give appropriate acknowledgements nor are they aware of the need to do so in accordance with the Creative Commons concept. Furthermore, 30\% admit they download music or movies illegally very frequently. In this sense a considerable share of the participants does not comply with the rules of behavior required for digital integrity.

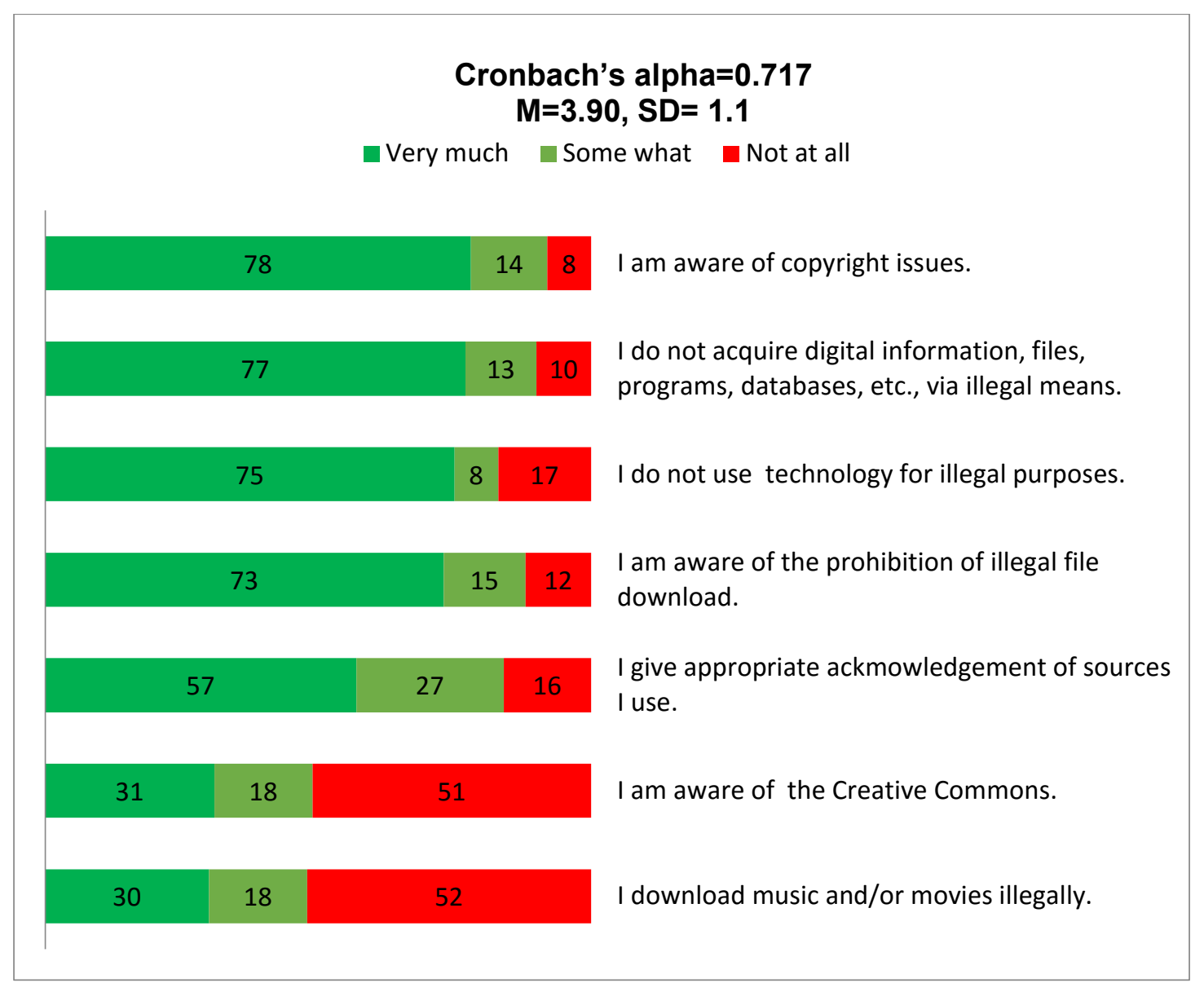

Figure 7: Digital integrity

\section{Summary and Future Research Planes}

The main purpose of the current research was to gather empirical evidence regarding the firmness of a digital literacies inventory developed by the research team. This innovative inventory was built based upon an extensive review of literature, examination of definitions, concepts, casestudies and theoretical models that deal with the $21^{\text {st }}$ century digital skills required for learning. Our preliminary findings suggest a statistical validation of the inventory. 
Based on findings among a selective population experienced in the use of digital literacies for learning, it can be concluded that most of the participants evaluate themselves as digitally literate with regard to the basic information research and retrieval skills as well as validation and information management. But when it comes to PS that require complex decision making or higher order thinking strategies, it seems that a large number of participants lack these skills. Also, a number of students perform the learning task without knowing what is expected of them in terms of allocating relevant learning information. These findings imply that a considerable share of the participants lack learning skills appropriate for the $21^{\text {st }}$ century learning process. Social responsibility and digital integrity domains are perceived as known by the participants but are not reflected in their behavior - a significant percentage of respondents say they do not take any pro-active measures to enforce appropriate digital behavior or to avoid illegally downloaded music or movies. A surprising finding refers to one of the essential learning strategies in the eyes of educators - collaborative and cooperative learning. Although most respondents believe they know how to learn as a member of a team of learners, a large percentage do not like working with peers and prefer to learn independently.

Although the findings indicate a clear trend, they should be treated with caution. These findings can be partly explained by the fact that the research population was selective, relatively mature, and experienced, for better or for worse, in the use of digital literacies for learning. This fact limits its generalizability to a wider population. However, the participants' answers provide a statistical firmness of the inventory that can be further tested in Israel and in international settings.

\section{References}

Anderson, R. E. (1982). National computer literacy program. In R. J. Seidel, R. E. Anderson, \& B. Hunter (Eds.), Computer literacy: Issues and directions for 1985 (pp. 3-17). New York: Academic Press.

Avgerinou, M., \& Ericson, J. (1997) A review of the concept of visual literacy. British Journal of Educational Technology, 28(4), 280-291.

Bawden, D. (2001). Information and digital literacies: A review of concepts. Journal of Documentation, $57(2), 218-259$.

Bawden, D. (2008). Origins and concepts of digital literacy. Digital literacies: concepts, policies and practices, 17-32.

Beaudoin, M., Kurtz, G., Jung, I., Suzuki, K. \& Grabowski, B. (2013). Online learner competencies: Attitudes, knowledge, and skills for successful learning. USA: Information Age Publishing.

Belshaw, D. (2012). What is' digital literacy'? A pragmatic investigation (Doctoral dissertation, Durham University).

Core Curriculum Evaluation Report (October 2004). Stephen F. Austin State University. Retrieved March 15, 2016, from http://www.sfasu.edu/research/Reports/GES/sfacorerpt.pdf

Dede, C. (2010). Comparing frameworks for 21 st century skills. 21st century skills: Rethinking how students learn, 51-76.

Dudeney, G., Hockly, N., \& Pegrum, M. (2013). Digital literacies. Harlow: Pearson

Eshet-Alkalai, Y., \& Amichai-Hamburger, Y. (2004). Experiments in digital literacy. Cyber Psychology \& Behavior, 7(4), 421-429.

Fieldhouse, M., \& Nicholas, D. (2008). Digital literacy as information savvy: The road to information literacy. In C. Lankshear \& M. Knobel (Eds.), Digital literacies: concepts, policies and practices (pp. 4771), Switzerland: Peter Lang.

Gilster, P. (1997). Digital literacy. New York: Wiley.

Hockly, N. (2012). Digital literacies. ELT Journal, 66(1), 108-112. 
Jung, I. S., \& Latchem, C. (Eds). (2011). Quality assurance and accreditation in distance education and elearning: Models, policies and research. New York and London: Routledge.

Lankshear, C., \& Knobel, M. (Eds.). (2008). Digital literacies: Concepts, policies and practices (Vol. 30). Peter Lang.

Lau, W. F., \& Yuen, A.H. K. (2014). Developing and validating of a perceived ICT literacy scale for junior secondary school students: Pedagogical and educational contributions. Computers \& Education 78, 19.

Littlejohn, A., Beetham, H., \& McGill, L. (2012). Learning at the digital frontier: A review of digital literacies in theory and practice. Journal of Computer Assisted Learning, 28(6), 547-556.

Longstreet, W. S., \& Sorant, P. E. (1985). Computer literacy--Definition?. Educational Horizons, 63(3), $117-20$.

Luehrmann, A. (1981). Computer literacy-What should it be? The Mathematics Teacher, 682-686.

Martin, A. (2008) Digital literacy and the 'digital society'. In C. Lankshear, \&M. Knobel, Digital literacies: concepts, policies and practices. New York: Peter Lang.

Mioduser, D., Nachmias, R., \& Forkosh-Baruch, A. (2008). New literacies for the knowledge society. In J. Voogt \& G. Knezek (Eds.), International handbook of information technology in primary and secondary education (pp. 23-42). USA: Springer.

Nelson, K., Courier, M., \& Joseph, G. W. (2011). Teaching tips: An investigation of digital literacy needs of students. Journal of Information Education, 22(2), 95-109.

Nunnally, J. C. (1978). Psychometric theory (2nd ed.). New York, NY: McGraw-Hill.

Pegrum, M. 2010. "I link, therefore I am": Network literacy as a core digital literacy. E-learning and Digital Media, 7(4), 346-354.

Watt, D. H. (1982). Education for citizenship in a computer-based society. In R. J. Seidel, R. E. Anderson, $\&$ B. Hunter (Eds.), Computer literacy: Issues and directions for 1985 (pp. 53-68). New York: Academic Press.

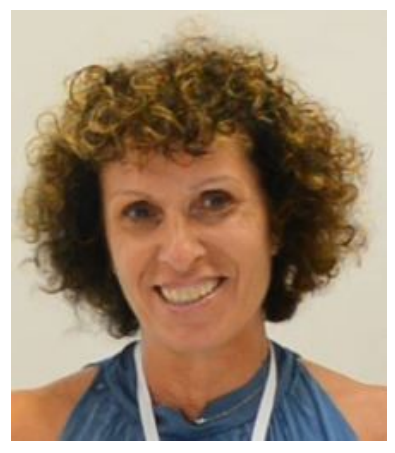

\section{Biographies}

Gila Kurtz (Ph.D.) is a Senior Lecturer and Head of MA program on ICT and Learning at The College for Academic Studies, Israel. Gila is the Editor-in- Chief of The Interdisciplinary Journal of e-Skills and Lifelong Learning: (IJELL). Her research include social networking sites for education, digital literacies and mobile learning.

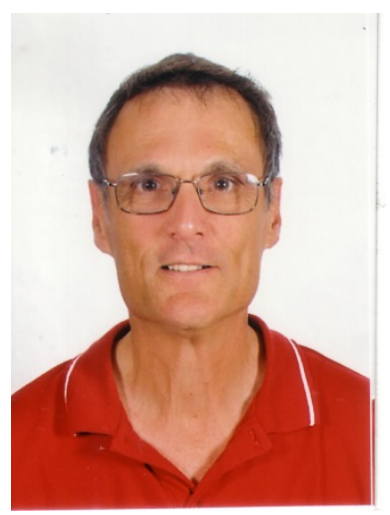

Yehuda Peled is a Senior Lecturer and the head of the information studies department at the Western Galilee College - Israel. He holds a Ph.D. in Educational Technology from the Technion - Israel Institute of Technology - Haifa.

His research interests include the use of collaborative environments in teaching and learning, various aspects of online and F2F academic dishonesty, Cyberbullying as well as organizational aspects of technology adoption in education. 